\title{
Scleroderma and dentistry: Two case reports
}

Shantanu Dixit ${ }^{1 *}$, Chaithra Kalkur ${ }^{2}$, Atul P. Sattur ${ }^{3}$, Michael M. Bornstein ${ }^{4}$ and Fred Melton ${ }^{5}$

\begin{abstract}
Background: Scleroderma is a chronic connective tissue disorder with unknown etiology. It is characterized by excessive deposition of extracellular matrix in the connective tissues causing vascular disturbances which can result in tissue hypoxia. These changes are manifested as atrophy of the skin and/or mucosa, subcutaneous tissue, muscles, and internal organs. Such changes can be classified into two types, namely, morphea (localized) and diffuse (systemic). Morphea can manifest itself as hemifacial atrophy (Parry-Romberg syndrome) although this remains debatable. Hence, we present a case of morphea, associated with Parry-Romberg syndrome, and a second case with the classical signs of progressive systemic sclerosis.
\end{abstract}

Case presentation: Case one: A 20-year-old man of Dravidian origin presented to our out-patient department with a complaint of facial asymmetry, difficulty in speech, and loss of taste sensation over the last 2 years. There was no history of facial trauma. After physical and radiological investigations, we found gross asymmetry of the left side of his face, a scar on his chin, tongue atrophy, relative microdontia, thinning of the ramus/body of his mandible, and sclerotic lesions on his trunk. Serological investigations were positive for antinuclear antibody for doublestranded deoxyribonucleic acid and mitochondria. A biopsy was suggestive of morphea. Hence, our final diagnosis was mixed morphea with Parry-Romberg syndrome.

Case two: A 53-year-old woman of Dravidian origin presented to our out-patient department with a complaint of gradually decreasing mouth opening over the past 7 years. Her medical history was noncontributory. On clinical examination, we found her perioral, neck, and hand skin to be sclerotic. Also, her fingers exhibited bilateral telangiectasia. An oral examination revealed completely edentulous arches as well as xerostomia and candidiasis. Her serological reports were positive for antinuclear antibodies against centromere B, Scl-70, and Ro-52. A hand and wrist radiograph revealed acro-osteolysis of the middle finger on her right hand. Hence, our final diagnosis was progressive systemic sclerosis.

Conclusion: Through this article, we have tried to emphasize the importance of a general examination when diagnosing rare systemic diseases such as scleroderma and the role of the general dentist when caring for such patients, even though they can be quite rare in general practice.

Keywords: CREST syndrome, Localized scleroderma, Morphea, Parry-Romberg syndrome, Raynaud's phenomenon, Systemic sclerosis

\footnotetext{
* Correspondence: drshantanudixit@gmail.com

'Department of Oral Medicine and Radiology, Dhulikhel hospital, Kathmandu

University School of Medical Sciences, Dhulikhel, Nepal

Full list of author information is available at the end of the article
}

(c) The Author(s). 2016 Open Access This article is distributed under the terms of the Creative Commons Attribution 4.0 International License (http://creativecommons.org/licenses/by/4.0/), which permits unrestricted use, distribution, and reproduction in any medium, provided you give appropriate credit to the original author(s) and the source, provide a link to the Creative Commons license, and indicate if changes were made. The Creative Commons Public Domain Dedication waiver (http://creativecommons.org/publicdomain/zero/1.0/) applies to the data made available in this article, unless otherwise stated. 


\section{Background}

Scleroderma is a chronic sclerosing disease of the connective tissues. It derives its name from the Greek words scleros (hard) and derma (skin). Hidebound skin is an important and characteristic feature of this disease thereby making the name "hidebound disease" more popular $[1,2]$. The first description of this disease as a separate pathological entity was given by Carlo Curzio of Naples in 1752 [2, 3] and its first name, "sclerodermie," was given nearly a century later by Gintrac in 1847. For years, the disease was thought to be a dermatological disorder but after its distinctive characteristic of systemic involvement was proven, Goetz coined the term "progressive systemic sclerosis" in 1945 [2, 4].

Scleroderma exists in two forms: morphea (circumscribed scleroderma) and generalized/progressive (diffuse scleroderma). However, some articles have mentioned acrosclerosis (scleroderma of the peripheries associated with Raynaud's phenomenon) as a third form [5, 6]. Morphea (localized scleroderma) is again subdivided into five types, namely: plaque, generalized, bullous, linear, and deep [7, 8]. CREST syndrome (calcinosis cutis, Raynaud's phenomenon, esophageal dysfunction, sclerodactyly, and telangiectasia), a rare condition, is thought to be a heterogeneous variant of systemic scleroderma [9]. Similarly, Parry-Romberg syndrome (hemifacial atrophy) is thought to be another variant of scleroderma. However, this remains debatable $[8,10,11]$.

Scleroderma was described as a pathological entity in the mid-eighteenth century but to date the exact etiopathogenesis is still unknown, possibly because of the disease's rarity. However, it is understood that age, gender, genetic, and environmental factors can influence vulnerability for the disease [2]. Some authors have suggested viral or bacterial infection (Borrelia burgdorferi), particularly in the case of morphea, as the causative agent. But sufficient evidence to support such claims is lacking [8]. Untimely interaction of immunity with the vascular system resulting in endothelial damage is also hypothesized as a major contributor for the initiation and progression of the disease $[2,12]$.

Systemic sclerosis (diffuse/generalized/progressive scleroderma) initially manifests itself as pitting edema of the skin which progresses to a thickening and hardening of the skin. The systemic form can involve multiple organs, such as the kidneys, lungs, heart, and the gastrointestinal system, among which the involvement of the latter is most common. These organs are affected either by fibrosis or by a diminished blood supply. Raynaud's phenomenon (paroxysmal vasospasm), claw-like fingers, hyperpigmentation, telangiectasia, and subcutaneous calcification are other common systemic manifestations that can be seen. Oral and facial tissues are the most affected, manifesting as the characteristic mask-like face (Mona Lisa face), constricted lips (fish mouth), a narrowing and stiffening of the tongue (chicken tongue), microstomia, pseudoankylosis, resorption of the mandibular angle, xerostomia, dental caries, and a widening, radiographically, of periodontal ligaments $[2,13]$. Oral ulceration, secondary to gastroesophageal reflux disease (GERD), is also reported in some cases [6]. Most of the time, as a result of these manifestations, patients visit dentists for these aesthetical and facial dysfunctions.

Morphea (localized scleroderma), on the other hand, causes localized fibrosis similar to scleroderma, resulting in localized indurated lesions [14]. As mentioned earlier, morphea can be subdivided into five different types. Mixed forms, such as localized scleroderma of the face with plaque/linear morphea at some other site, have been reported in the literature [15].

The face is the most common site for the linear type of morphea with fibrosed tissue appearing as a sabre cut (en coup de sabre) resulting in facial hemiatrophy mimicking Parry-Romberg syndrome [2]. Hence, with this article we are presenting two such cases of scleroderma reporting to us with aesthetical and facial dysfunctions. Both cases were later diagnosed as mixed morphea, with Parry-Romberg syndrome, and progressive systemic sclerosis, respectively.

\section{Case presentation}

\section{Case one}

A 20-year-old man of Dravidian origin presented to our Department of Oral Medicine and Radiology with the chief complaint of facial asymmetry over the past 2 years. According to him, and on review of photographs he had brought, his facial symmetry was within normal limits prior to these past 2 years. He also reported difficulty in articulation and a loss of taste sensation. He also presented with skin lesions on his trunk (abdomen and back).

His medical and family histories were noncontributory. On general examination, he was found to be conscious and oriented. His vital signs were within normal range. He had limited, well-circumscribed, and oval-shaped hyperpigmented lesions on his abdomen and back (Fig. 1). These lesions appeared fibrotic on palpation. A head and neck examination revealed gross asymmetry of the left side of his face and there was a sharp demarcation on his chin, separating the normal and abnormal side (Fig. 2).

A visually evident loss of fat, muscles, and subcutaneous tissue resulted in a shrunken appearance to the left side of his face. His left ear pinna appeared to be fibrosed on palpation. Skin on the affected side appeared to be sclerotic. An ocular examination disclosed no abnormalities. An intraoral examination revealed shrunken and rigid left side of his tongue otherwise his mucosa appeared to be normally moist (Fig. 3). A hard tissue examination offered no relevant findings. 


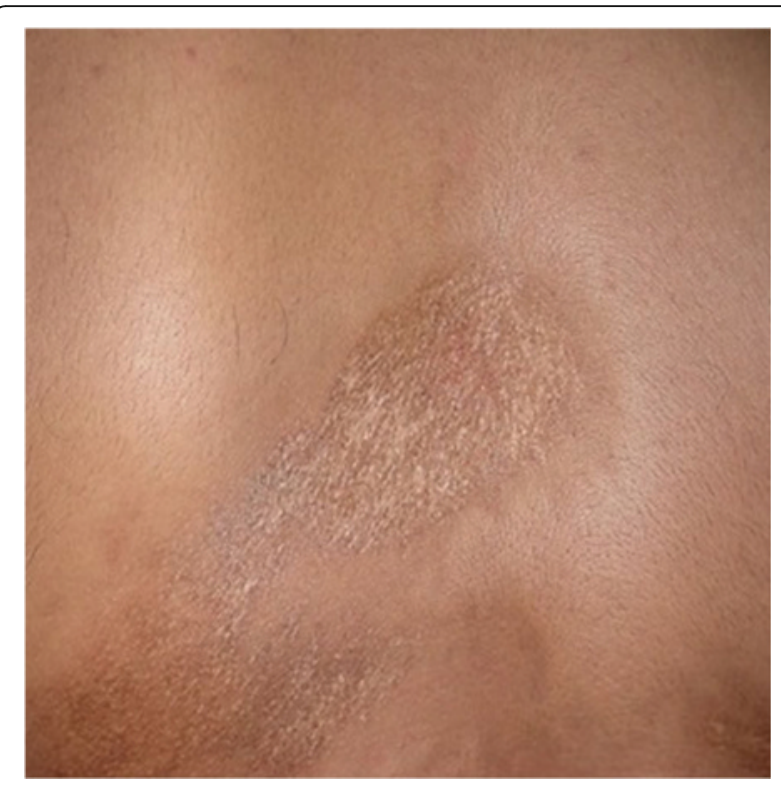

Fig. 1 Morphea seen on trunk (back) of patient

Hence, our provisional diagnosis was facial hemiatrophy with plaque morphea and further investigation was recommended.

Panoramic view showed relative microdontia on the left side, with a thinning of his mandibular body and ramus (Fig. 4). Submentovertex and posteroanterior views also revealed gross asymmetry of the left side of his jaw. Serological investigations were positive for double-stranded deoxyribonucleic acid (DNA) and antimitochondrial antibody; however, his erythrocyte sedimentation rate (ESR) levels were normal.

Fundoscopic examination of his eyes and audiometry showed no abnormalities. Ultrasonography examinations of his bilateral buccal mucosa and parotid glands were normal. A skin biopsy revealed a thickened epidermis with sparse adnexal structures. Thickened and closely packed collagen bundles in reticular dermis, along with hypocellularity and sparse lymphoplasmacytic infiltrate in the dermis, were suggestive of morphea.

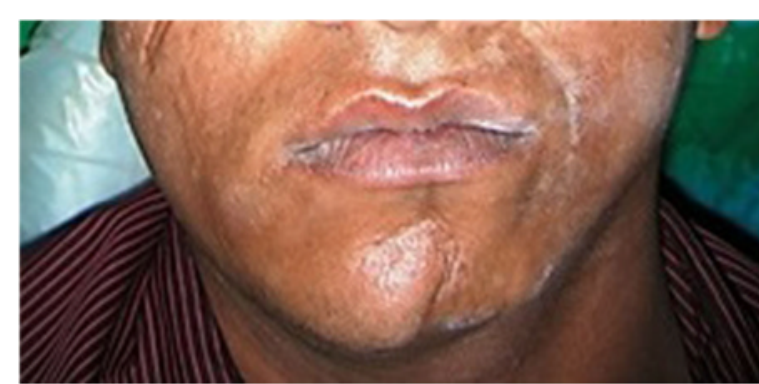

Fig. 2 Gross asymmetry of face (left side) with "en coup de sabre" on chin

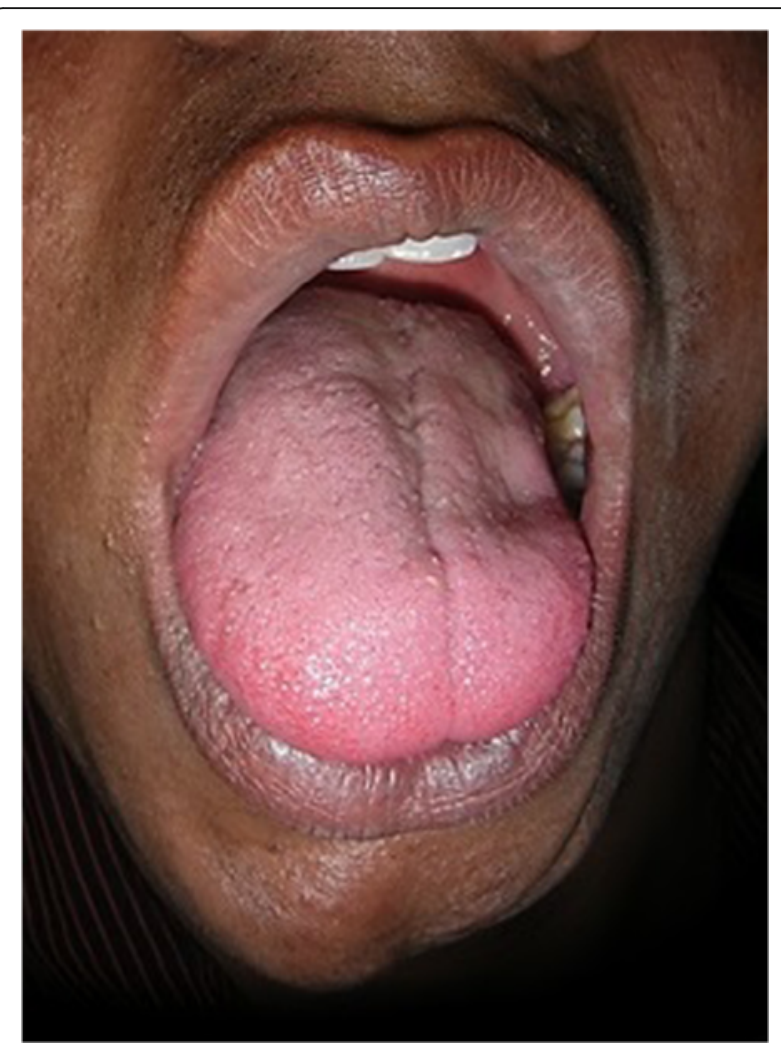

Fig. 3 Atrophy of tongue (left side)

After correlating these findings with the available literature, the final diagnosis of mixed morphea with Parry-Romberg syndrome was given.

\section{Case two}

A 53-year-old woman of Dravidian origin visited our department complaining of difficulty in using her complete dentures as a result of the gradual reduction in mouth opening over the previous 7 years. She also complained of a burning sensation of her oral mucosa (predominantly in her palate) and a tightness of the skin in her perioral and neck regions. On clinical examination

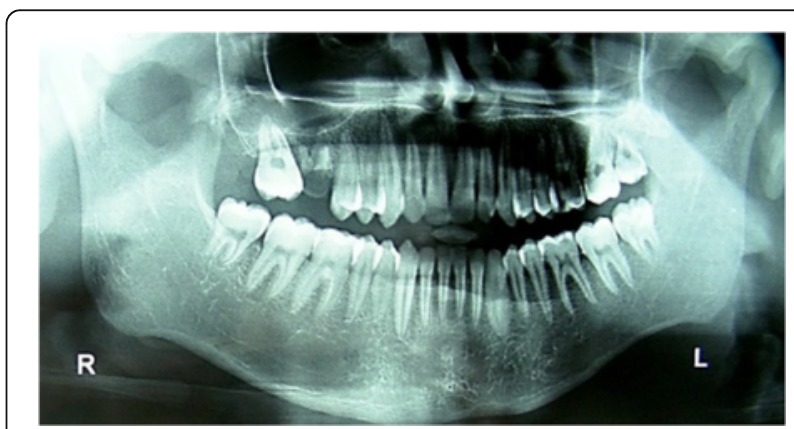

Fig. 4 Panoramic view showing gross asymmetry of face (left side) with relative microdontia and thinning of ramus/body of mandible 
we found her face to be expressionless. On palpation, the skin of her perioral and neck regions was sclerotic (Fig. 5). The skin on her fingers also appeared to be pale on inspection and indurated when palpated. According to our patient, this paleness spreads symmetrically to all ten fingers when exposed to cold, suggestive of Raynaud's phenomenon. Her fingers also showed areas of telangiectasia (Fig. 6). An oral examination revealed completely edentulous maxillary and mandibular arches, microstomia due to rigid perioral skin, xerostomia (positive tongue blade test), and an erythematous patch on her palate. The clinical findings were suggestive of progressive systemic sclerosis; hence, we recommended radiological and serological investigations. For the erythematous lesion, a swab was taken and was sent for culture. These investigative reports were consistent with our provisional diagnosis.

The serological reports were positive for increased serum C3 level and a ribonucleic acid (RNA) profile was positive for centromere B, Scl-70, and Ro-52, explaining her inability to use her prostheses with which she had been comfortable 7 years prior. In addition, a radiograph of her hand and wrist revealed reabsorption of the terminal phalanges (acro-osteolysis) of the middle finger on her right hand (Fig. 7). A swab culture was positive for candidiasis, which reflected alteration of her oral microflora secondary to xerostomia, resulting in a burning sensation.

\section{Discussion}

Progressive/diffuse/generalized sclerosis is more common in the fourth to sixth decades of life and it affects females more than males with a 3 to $6: 1$ ratio, respectively [16]. The American College of Rheumatology has recommended criteria for the diagnosis of systemic scleroderma with the major criterion as proximal diffuse (truncal)

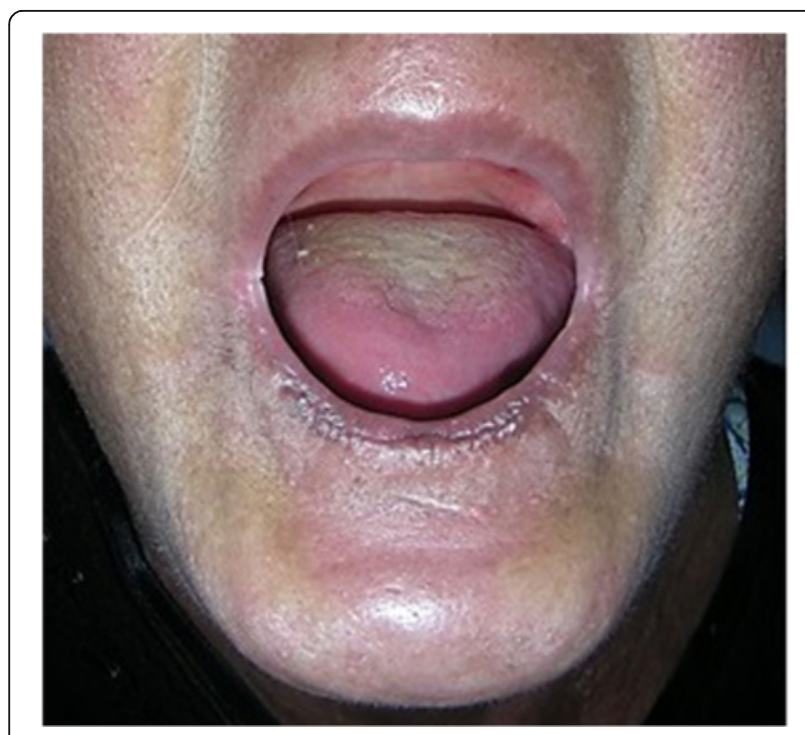

Fig. 5 Microstomia resulting in difficult prosthesis placement

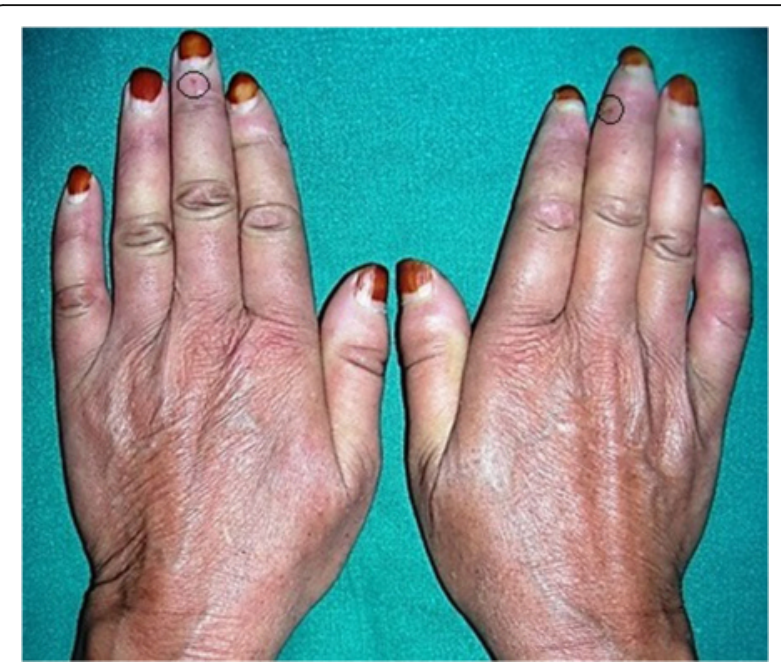

Fig. 6 Shiny and tense skin of hand showing Raynaud's phenomenon and telangiectasia (encircled)

sclerosis (skin tightness, thickening, non-pitting induration). Minor criteria include: sclerodactyly (only fingers and/or toes), digital pitting scars or loss of substance of the digital finger pads (pulp loss), and bibasilar pulmonary fibrosis.

Our second case fulfils the major criteria of symmetrical thickening of the skin proximal to the metacarpophalangeal joint, as shown in Fig. 6. Our patient also exhibited Raynaud's phenomenon, along with other cardinal features, which are the most common and earliest manifestations of the disease in $95 \%$ of cases, as suggested by Lester et al. [14] and other authors [6]. Localized scleroderma/morphea is more common in white women with a female to male ratio of 2 to $4: 1$ and an incidence rate of 0.3 to 3 cases per 100,000 individuals/year.

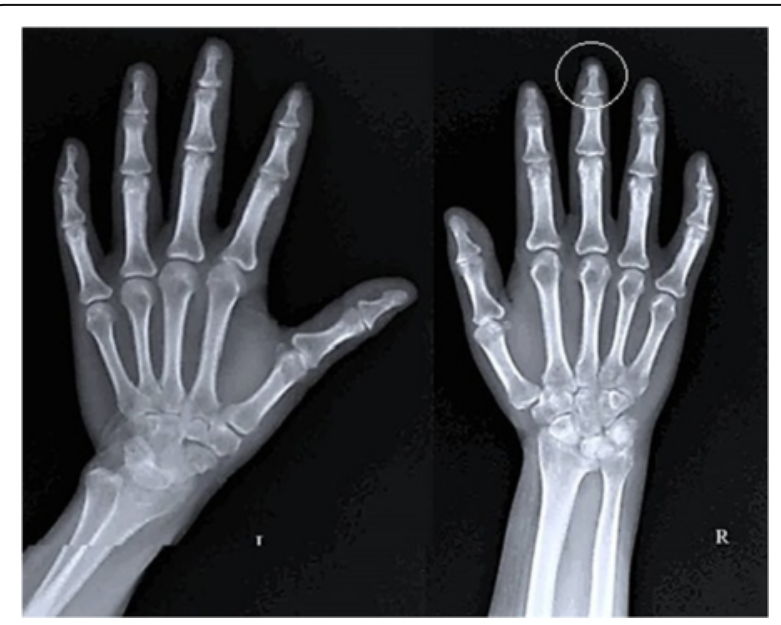

Fig. 7 Hand and Wrist radiograph revealing acro-osteolysis (encircled) of terminal phalanges of right middle finger 
Morphea (localized scleroderma) causes localized fibrosis without systemic involvement and exists in five different forms but also can persist in "mixed form" where localized scleroderma of the face can be associated with plaque morphea or linear scleroderma affecting other parts of the body, most often the trunk. Linear scleroderma, a subtype of morphea, is strongly associated with Parry-Romberg syndrome (facial hemiatrophy); however, the relationship is debatable. Linear scleroderma is characterized by unilateral atrophies of the skin, subcutaneous tissues, muscles, and underlying bone structures with neurological deficits [8]. Authors have mentioned the coexistence of en coup de sabre or linear scleroderma with Parry-Romberg syndrome in $42 \%$ of cases [17]. Tollefson and Witman [18] have also reported this overlapping of the two different diseases in $36.6 \%$ of patients. Our second case was an illustration of the coincidence of these two diseases. Differential diagnosis of scleroderma on the basis of vascular changes can be primary Raynaud's phenomenon, physical trauma, chemical exposure, and drugs and/or toxins. On the basis of skin changes, amyloidosis, insulin-dependent diabetes mellitus, metabolic-genetic disorder, and overlap syndrome can be the differential diagnoses. Ageing, sarcoidosis, amyloidosis, and autoimmune connective tissue disease can be considered in the differential diagnosis in cases of visceral involvement [2].

There are different autoantibodies which are extremely helpful in forecasting different subtypes of scleroderma. However, autoantibody absence does not preclude the diagnosis of this disease as $20 \%$ of the patients with different subtypes of scleroderma do not show these antibodies. Highly specific antinuclear antibodies (ANA) for scleroderma include anti-single-stranded, antihistone, and anti-topoisomerase antibodies. Some other ANA that commonly present in scleroderma include anticentromere, anti-U3-RNP, anti-Th, anti-fibrillin, antiphospholipid, and antimitochondrial antibodies [19-21]. Both of our cases were positive for a few of these serological markers and the markers were extremely helpful in yielding a final diagnosis.

Treatment of these types of cases is vastly difficult to plan as the exact etiology for this disease is not exactly known. Medical treatments include topical, intralesional, or systemic glucocorticoids, vitamin E, Vitamin D3, retinoid, penicillin, griseofulvin, and interferon-alpha. For those with a more severe and progressive disease, treatment includes methotrexate (for which there is limited evidence in linear scleroderma), corticosteroids, cyclophosphamide, and azathioprine, although it remains unclear as to how beneficial such treatment modalities are. Surgical intervention includes restorative plastic surgery (fat or silicone implants, flap/pedicle grafts, or bone implants) [22, 23].
Preservation or replacement of the existing dentition is a great challenge for a dentist in these cases. Patients should be instructed regarding the importance of maintaining proper oral hygiene and counseled frequently in order to prevent the patient undergoing depression due to the challenging nature of the disease. Mouth dilator exercises such as increasing the number of tongue blades/ ice cream sticks between the posterior teeth, should be encouraged. Difficulty in holding a toothbrush secondary to sclerodactyly can be overcome by advising patients to use adaptive devices such as electric toothbrushes, Waterpik flossers, and floss forks. Temporomandibular/myofacial pain dysfunction can be treated with the use of muscle relaxants, physiotherapy, and dental appliances. Dysgeusia and dental caries secondary to xerostomia can be avoided by advising the use of artificial saliva, sugar free candies, fluoride toothpaste and medications like pilocarpine [2]. In severe cases, surgical procedures, such as commissurotomy, are recommended to increase mouth opening [24].

\section{Conclusions}

With these two case reports we have tried to elucidate the effects of systemic and localized scleroderma in the maxillofacial region, as well as discuss systemic manifestations. Appropriate management of scleroderma requires frequent consultations with a rheumatologist but general dentists should monitor patients with scleroderma by performing frequent clinical and radiological examinations so as to follow the course of the disease and to meet its dental challenges.

\section{Acknowledgements \\ We would like to acknowledge both the patients and their families for allowing us to use their data in our case report and allowing their cases to be published. We would also like to thank our reviewers for reviewing this report and for their valuable suggestions and comments. No funding was utilized for this report.}

Funding

This work is not funded.

Availability of data and supporting materials Not applicable.

\section{Authors' contributions}

SD, CK, APS, and MB participated in the conception and design of this report and were involved in drafting and revising the manuscript. FM performed the final revisions of the manuscript. All authors read and approved the final manuscript.

\section{Competing interests}

The authors declare that they have no competing interests.

\section{Consent for publication}

Written informed consent was obtained from the patients for publication of this case report and any accompanying images. A copy of the written consent is available for review by the Editor-in-Chief of this journal.

Ethics approval and consent to participate Not applicable. 


\section{Author details}

'Department of Oral Medicine and Radiology, Dhulikhel hospital, Kathmandu University School of Medical Sciences, Dhulikhel, Nepal. ${ }^{2}$ Department of Oral Medicine and Radiology, Century International Institute of Dental Science and Research Centre, Kasargod, Kerala, India. ${ }^{3}$ Department of Oral Medicine and Radiology, SDM College of Dental Sciences, Sattur, Karnataka, India. ${ }^{4}$ Department of Oral Surgery and Stomatology, School of Dental Medicine, University of Bern, Bern, Switzerland. ${ }^{5}$ General Practitioner, Wenatchee, Washington, USA.

Received: 28 September 2016 Accepted: 3 October 2016 Published online: 24 October 2016

\section{References}

1. Ahathya RS, Deepa Lakshmi D, Emmadi P. Systemic sclerosis. Indian J Dent Res. 2007;18:27-30

2. Vikram B, et al. A rare case of hidebound disease with dental implications. Dent Res J (Isfahan). 2013;10(4):556-61.

3. Naylor WP. Oral management of scleroderma patient. J Am Dent Assoc. 1982;105:814-7.

4. Goetz RH. The pathology of progressive systemic sclerosis with special reference to changes in the viscera. Clin Proc. 1945:4:337-92.

5. Alexandridis C, White SC. Periodontal ligament changes in patients with progressive systemic sclerosis. Oral Surg Oral Med Oral Path. 1984:58:113-8.

6. Anbiaee N, Tafakhori Z. Early diagnosis of progressive systemic sclerosis (scleroderma) from a panoramic view: report of three cases. Dentomaxillofac Radiol. 2011;40(7):457-62.

7. Peterson LS, et al. Classification of morphea (Localized Scleroderma). Mayo Clin Proc. 1995;70:1068-76.

8. Careta MF, Romiti R. Localized scleroderma: clinical spectrum and therapeutic update. An Bras Dermatol. 2015;90(1):62-73.

9. Neville BW, Damm DD, Allen CM, Bouquot JE. Oral and maxillofacial pathology. 3rd ed. St Louis: Elsevier/Saunders; 2009. p. 799.

10. Gambichler T, et al. Bilateral linear scleroderma "En coup de sabre" associated with facial atrophy and neurological complications. BMC Dermatol. 2001;1:9.

11. Vierra E, Cunningham BB. Morphea and localized scleroderma in children. Semin Cutan Med Surg. 1999;18:210-25.

12. Lever WF, Schaumburg-Lever G. Histopathology of the Skin. 6th ed. Philadelphia: JB Lippincott Co; 1983. p. 464-6.

13. Caplan HI, Benny RA. Total osteolysis of the mandibular condyle in progressive systemic sclerosis. Oral Surg Oral Med Oral Path. 1978;46:362-6.

14. Lester WB, Martin SG, Michael G, Jonathan AS. In: Greenberg M, Glick M, Ship JA, editors. Burket's oral medicine: Diagnosis and treatment. Immunologic diseases. 11th ed. New York: JB Lippincott Publishing Co. Ltd; 2008. p. 451.

15. Marzano AV, et al. Localized scleroderma in adults and children. Clinical and laboratory investigations on 239 cases. Eur J Dermatol. 2003;13:171-6.

16. Cawson RA, Odell EW. Cawson's essentials of oral pathology and oral medicine. 8th ed. London: Churchill Livingstone; 2008. p. 195.

17. Sommer A, et al. Clinical and serological characteristics of progressive facial hemiatrophy: a case series of 12 patients. J Am Acad Dermatol. 2006;54:227-33.

18. Tollefson MM, Witman PM. En coup de sabre morphea and Parry-Romberg syndrome: a retrospective review of 54 patients. J Am Acad Dermatol. 2007:56:257-63.

19. Takehara K, Sato S. Localized scleroderma is an autoimmune disorder. Rheumatology. 2005;44:274-9.

20. McPhee SJ, Papadakis M, Rabow MW. Current Medical Diagnosis and Treatment. 51st ed. USA: McGraw-Hill companies, Inc; 2012. p. 815-7.

21. Chung L, Utz PJ. Antibodies in Scleroderma: Direct Pathogenicity and Phenotypic Associations. Curr Rheumatol Rep. 2004;6(2):156-63.

22. Hunzelmann $\mathrm{N}$, et al. Management of localized scleroderma. Semin Cutan Med Surg. 1998;17:31-4.

23. Stone J. Parry-Romberg syndrome. Pract Neurol. 2006;6:185-8.

24. Johns FR, Sandler NA, Ochs MW. The use of a triangular pedicle flap for oral commissuroplasty: Report of a case. J Oral Maxillofac Surg. 1998:56:228-31.

\section{Submit your next manuscript to BioMed Central and we will help you at every step:}

- We accept pre-submission inquiries

- Our selector tool helps you to find the most relevant journal

- We provide round the clock customer support

- Convenient online submission

- Thorough peer review

- Inclusion in PubMed and all major indexing services

- Maximum visibility for your research

Submit your manuscript at www.biomedcentral.com/submit 